\title{
РАЗВИТИЕ И ОБУЧЕНИЕ: ПРИ КАКИХ УСЛОВИЯХ ОБУЧЕНИЕ МПЖЕТ СТАТЬ «РАЗВИВАЮЩИМ»?
}

\author{
Нечаев Николай Николаевич
}

Статья посвящена методологическим проблемам исследования зацеленаправленнои на развитие субъекта деятельности (в основу статьи положен ряд выступлений автора по проблеме взаимосвязи обучения и развития, состоявшихся на ряде Международных и Всероссийских конференций в период 2012-2015 г2. - прим. Н. Н.).

Показано, что в отечественной психологии господствует педагогизированная трактовкаразвития, что проявляется как в характеристике

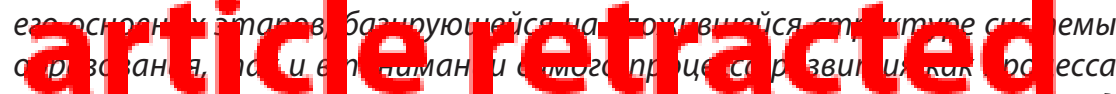
усвоения социального опыта. Тем самым практически игнорируется взгляд на развитие как на процесс самодвижения деятельности, определяемого «вызреванием» внутренних противоречий ее осуществления в конкретном социально-историческом контексте, структура которого, в свою очередь, зависит от характерного для данного общества способа производства и основных противоречий его социально-экономического развития.

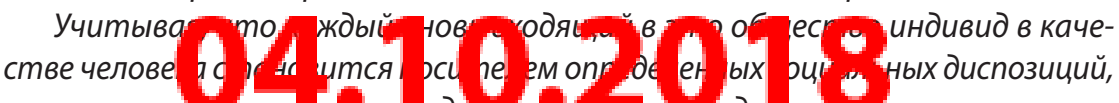
то "механизил развитая есо деяпелюнипи определяети как разрешение противоречий, возникающих в ходе включения этого индивида в совместную деятельность. С психологической точки зрения эти противоречия - в зависимости от этапа и периода развития деятельности - выступают либо как противоречие между сложившимися способами действия и складывающейся в деятельности субъекта системой отношений, в которые с момента рождения объективно включен субъект, либо как противоречие между сложившейся системой отношений и складывающимися способами действия, которые в конкретно-психологическом плане выражаются в дифференцировке мотивационных предпочтений личности на каждом этапе развития ее деятельности. 


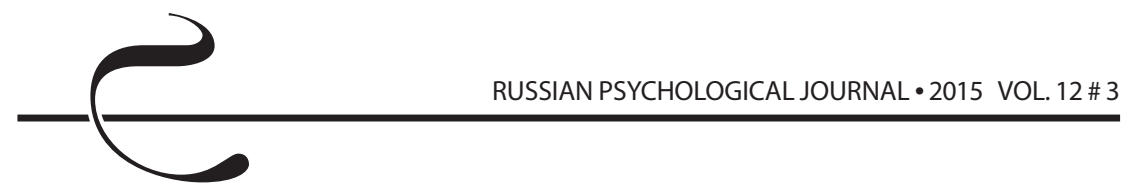

Особое внимание уделяется зависимости форм проявления закономерностей процесса развития от конкретных условий и содержания совместной деятельности, частной формой которой является обучение.

На основе предлагаемого представления о механизмах развития деятельности делается вывод о том, что «развивающий» характер обучения определяется тем, на каком этапе развития находится деятельность субъекта, для которого мом' "зачионно значимыми могут становиться либо операциональные возможности, предлагаемые обучением, либо его вхождение в новую систему отношений.

Ключевые слова: развитие деятельности, усвоение опыта, периодизация развития, совместная деятельность, система отношений, способы

Хотя в течение ряда десятилетий мой исследовательский интерес был связан с психолого-педагогической проблематикой высшего образования, тему взаимосвязи обучения и развития вряд ли можно назвать побочной. В данном случае, следуя логике великих философов, я исхожу из того, что понимание закономерностей развития деятельности на ее высших уровнях

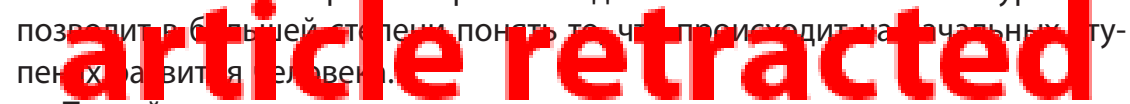

Точкой отсчета здесь может служить важное в данном контексте высказывание Л. С. Выготского: «Для диалектически-материалистического мышления проблема развития является центральной и основной для всех областей действительности и для всех областей научного знания. Однако не всякое решение этой проблемы приближает нас к истинному пониманию объективной диалектики действительности. Этому истинному пониманию противостоят

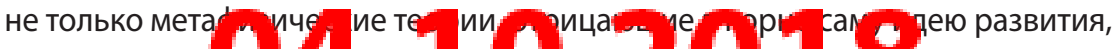



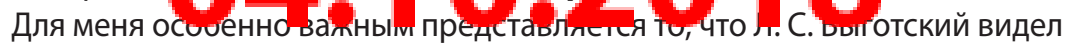
проблему развития как центральную, по сути, основополагающую для всех областей науки и практики, одновременно подчеркивая опасность «ложных идей развития», которые и в отечественной и в зарубежной психологии, к сожалению, существуют и поныне.

Обратимся к обозначенным Л. С. Выготским аспектам проблемы.

Центральный характер проблемы развития предполагает, очевидно, то, что проблематика развития, обычно рассматриваемая в контексте возрастной и педагогической психологии, является столь же важной для общей психологии. Однако анализ сложившейся ситуации с общепсихологической трактовкой категории развития позволяет утверждать, что до 
сих пор многие исследования страдают натурализмом и «индивидностью» в понимании человека и его жизнедеятельности [22]. Однако, как отмечал К. Маркс, «индивид есть общественное существо. Поэтому всякое проявление его жизни, даже если оно и не выступает в непосредственной форме коллективного, совершаемого совместно с другими проявлениями жизни, - является проявлением и утверждением общественной жизни [20, т. 42, с. 118].

Действительно, общество планирует результаты развития настоящих и будущих поколений. Однако при этом большинство отечественных авторов придерживается точки зрения, сформулированной в трудах отцовоснователей отечественной психологии [8, 9, 17, 25 и др.], согласно которой

мы, т. е. старшее поколение - носители этого опыта, темили иным способом предлагаем этот опыт новому поколению, а дальше происходит процесс его усвоения, который мы же и организуем.

Этой укоренившейся точке зрения способствуют и традиционные психологические представления о процессе интериоризации как переходе некого «внешнего» содержания извне внутрь индивида $[5,8,30]$.

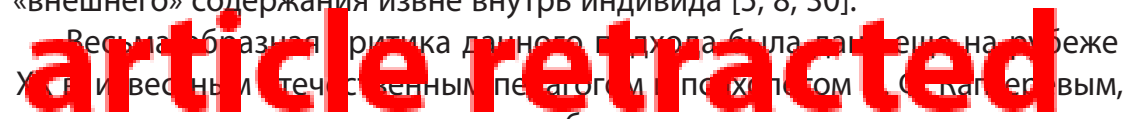
указавшим на ложность понимания образовательного процесса как своего рода «...трубки, по которой культура переливается от одного поколения к другому...» [14, с. 350]. К сожалению, это относится и к пониманию процесса интериоризации, выступающего таким образом в виде психологической характеристики этой трубки, по которой происходит «переливание опыта» от тех, кто им владеет, к тем, кто должен им овладеть. Поэтому

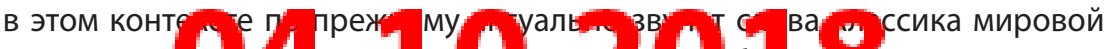

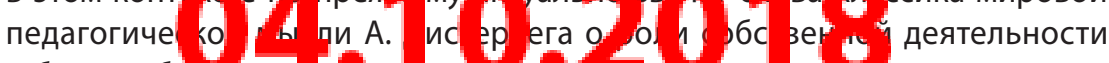
субъекта образования иразьития, которье он адресоьал нелецким учителям: «...Развитие и образование ни одному человеку не могут быть даны или сообщены (выделено мной. - Н. Н.). Всякий, кто желает к ним приобщиться, должен достигнуть этого собственной деятельностью, собственными силами, собственным напряжением» [11, с. 249]. Мысль эта - хорошо известна, но, к сожалению, мы слишком часто весьма поверхностно читаем и цитируем классиков, не задумываясь о тех следствиях, которые вытекают из принятия их точки зрения.

Таким образом, вся концептуальная парадигма «передачи» опыта, включающая такие понятия, как «усвоение», «присвоение», «научение» и т. п., требует коренного пересмотра или, по крайней мере, серьезного уточнения, 
которое прежде всего должно идти по линии разделения задач образования (обучения в широком смысле слова) и развития.

К сожалению, для современных психологов образование - не столько специально организуемый учебно-воспитательный процесс организации деятельности субъекта, в ходе которой осуществляется ее развитие, сколько сам процесс становления и развития человека в процессе совместной деятельности. Для нас, как ' п пя П. Ф. Каптерева, очевидно, что развитие необходимо рассматривать в его собственной логике, а образование выступает лишь как специально организуемый процесс, создающий те или иные условия для этого развития, причем отнюдь не всегда благоприятные с точки зрения планируемых результатов развития. В противном случае про-

Об этом свидетельствует и то, чтово многих серьезныхработах образование и развитие часто употребляются как синонимы, причем это происходит в разных отраслях психологической науки [8, 10, 17 и др.] и в различных сферах педагогической практики $[9,26,28]$. Достаточно напомнить, что само выделение ступеней возрастного развития в повсеместно используемой в отечественнойпсихологии периодизации [30] базируется на педагогиче-

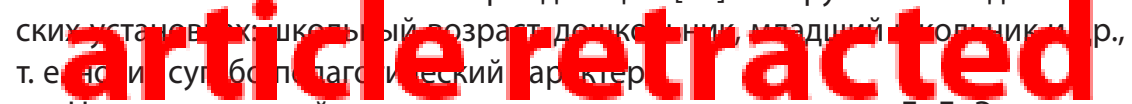

Недостатки такой периодизации хорошо понимал сам Д. Б. Эльконин, указывая, что «... членение детства на педагогических основаниях не связано с решением вопроса о движущих силах развития ребенка, о закономерностях переходов от одного периода к другому... и не в состоянии ответить на ряд существенных практических вопросов (например, когда надо начинать обучение в школе, в чем заключаются особенности воспитательно-образовательной

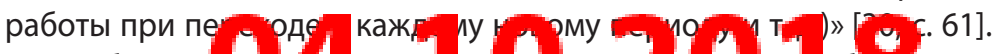

По большс уу чт «прив зк $\mathrm{p}$ звиту к ис емє об а. эвания неслучайна. На наш взтляд, Она показывает, что ичщесто и государство заинтересованы в том, чтобы процесс развития и его результаты рассматривались как закономерный «продукт» процесса воспроизводства «человеческого капитала», целенаправленной деятельности, задача которой - достижение нужных обществу и государству характеристик «конечного» продукта, предназначенного для потребления в системе общественного производства. Поэтому закономерно, что образование с этой точки зрения рассматривается как специально организуемый процесс «духовного» производства человека, направленный на развитие тех его психологических возможностей, в которых конкретно должна быть представлена специфика общественного бытия человека, т. е. его реального участия в системе сложившегося в данном 
обществе разделения труда, в системе соответствующих этому разделению общественных связей отдельных индивидов. Таким образом, с этой точки зрения развитие - это то, что получается в результате целенаправленной «образовательной» деятельности общества.

Значимость проблемы развития в психологии подтверждается множественностью и разнообразием соответствующих направлений психологических исследований. Есп' братиться к номенклатуре исследований, то среди них можно выделить работы, посвященные развитию т. н. психических процессов (восприятия, внимания, памяти, мышления и т. д.); развитию операционально-предметной и мотивационно-потребностной сферы; развитию эмоционально-волевых процессов и когнитивному развитию.

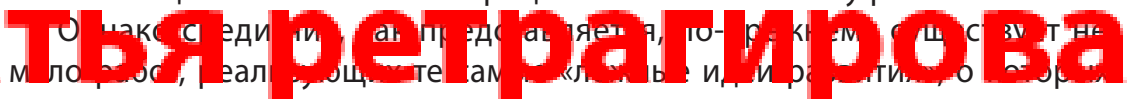
говорил Л. С. Выготский. Так, мнотие работы, связанные с исследованием психических процессов, построены на парциальном подходе к процессу развития, при котором каждый психический процесс рассматривается как нечто отдельное и самодостаточное. Простое перечисление исследований, посвященных «развитию» восприятия, памяти, внимания, мышления, в которых даже нет попыток соотносить получаемые результаты с аналогичными

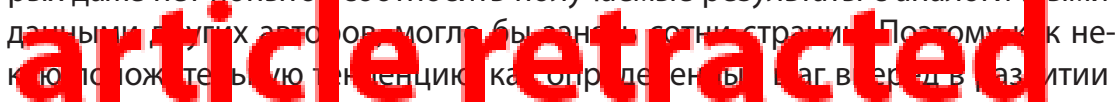
самой психологии, можно отметить исследования, ориентированные на «когнитивное развитие» в целом, поскольку в них укоренившаяся со времен В. Вундта «процессуальная» парадигма существования веера «психических» процессов как будто бы преодолевается.

Не останавливаясь подробно на каждой из отмеченных сфер, отметим в позитивном плане проблематику исследований развития личности, потому

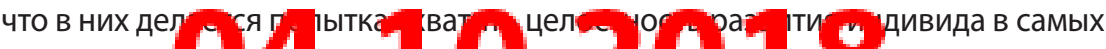

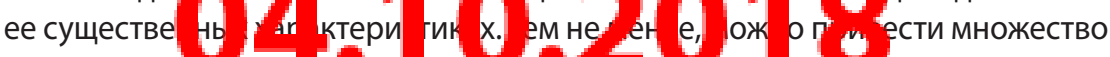
примеров, свидетельстующих отом, чилиразьитие личности рассматривается парциально: «здесь про личность, а там - про мышление».

Если обратиться к научным дневникам Д. Б. Эльконина, можно увидеть, что он тоже боролся с подобным «парциальным» подходом. Вот запись, датированная 31.10.1967 г.: «Что такое "психическое развитие"? Отрицательных определений сколько угодно. Это не только и не столько интеллектуальное, или, как его еще называют, умственное, развитие. Это не только и не столько так называемое развитие чисто познавательных процессов. Это не восприятие плюс память, плюс мышление, плюс воображение. Это не аффект плюс интеллект. Это не чистые, взятые сами по себе потребности и аффекты. ....Из сказанного следует только одно следствие: главная задача 


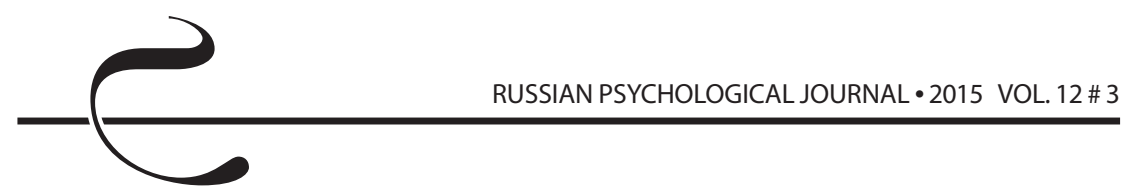

состоит в том, чтобы найти далее неразложимую единицу психического развития» [30, с. 489].

Замечание о необходимости поиска «единицы» психического развития вновь отсылает нас к Л. С. Выготскому с его призывом к анализу не по элементам, а по «единицам». Этот же методологический подход Д. Б. Эльконин использует применительно к проблеме развития в детской игре [30, с. 316].

Очевидно, что это можнс лт ' гсти вообще ко всякой целостности, которую мы подчас пытаемся рассмотреть на уровне отдельных составляющих, считая, что таким образом мы в конечном итоге получим целое. Для Д. Б. Эльконина было ясно, что это ложный ход, и если мы не понимаем собственную логику процесса развития, значит мы не можем планировать и сам процесс духовного что ни периодизация Ж. Пиаже, ни периодизация Л. С. Выготского не дают ответа на вопрос, почему ребенок переходит от одной стадии возрастного развития к другой [30, с. 64].

В самом деле, как осуществляется этот переход? Как люди самостоятельно «дорастают» до теоретических обобщений в своей деятельности, находясь вне системы развивающего обучения по В. В. Давыдову? Значит,

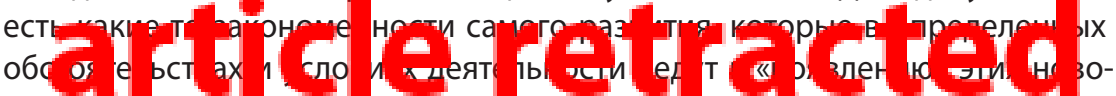
образований, несмотря на существующую систему образования. И, следовательно, и наши «образовательные» способы воздействия на процесс развития нельзя рассматривать как непосредственные «агенты», которые этот процесс определяют.

Необходимо согласиться с Д. Б. Элькониным, что психология не решает задачу раскрытия логики самого процесса развития, отличной от педагоги-

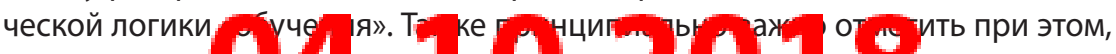

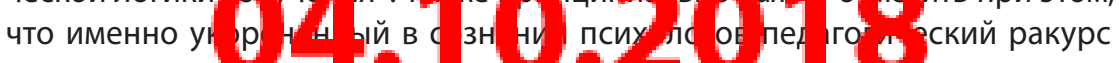
рассмотрения ироцесса развития засяавлге их трактовато этот процесс как исключительно прогрессивный и позитивно направленный: «...принято считать, - пишет В. И. Слободчиков, - что развиваться - это хорошо» [26, с. 13]; что развитие, - вторит ему Г. Г. Кравцов, - всегда происходит «в направлении совершенствования» $[16$, с. 58].

Подобный, по сути, обывательский подход в понимании развития, к его трактовке как некоего изначально заданного позитивного процесса, лежит в основе всех ныне существующих систем «развивающего обучения». Отсюда понятно, почему для многих исследователей «развивающее обучение» - это хорошее обучение, а «неразвивающее» - плохое. Но спросим себя: а может ли «развивающее» обучение быть «неразвивающим»? Это 
же некое противоречие в терминах. Очевидно, что при такой постановке вопроса развитие отождествляется с достижением желаемых позитивных результатов той или иной организации процесса образования, т. е. налицо педагогизированная трактовка развития.

При всем разбросе критериев «развивающего обучения»- будь то обучение по третьему типу ориентировки (П. Я. Гальперин) [9], система «развивающего» обучения Элькм' '’ 'а-Давыдова [10, 30], система Л. В. Занкова [13], «гуманистическая педагогика» Ш. А. Амонашвили [1], школа «диалога культур» В. С. Библера [28] - оказывается, что в контексте всех этих систем развитие рассматривается как успешное решение определенной педагогической задачи. Последняя заключается в определении условий раннего приобщестановится неким единообразнымрезультатом деятельности организаторов процесса развития.

Казалось бы, развивающее обучение с его ориентацией на самостоятельный «поиск истины» противостоит подобному единообразию. Однако на деле его подход к целям и задачам обучения, «ведущего» развитие, «чреват» психологически негативными последствиями для процесса развития.

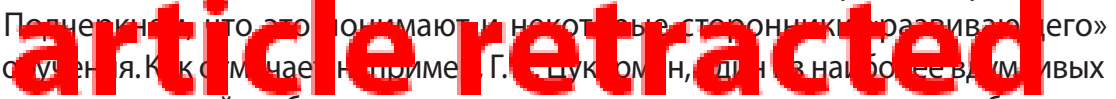
исследователей, работающих в русле концепции «развивающего» обучения по системе Эльконина-Давыдова, «...если перечисленные образовательные пространства будут предлагать ребенку действовать по образцам, правилам и инструкциям, то его развитие будет искривлено в одну сторону, если же во всех кружках, студиях и классах ребенка будут побуждать к поиску и инициативе, то его развитие будет тоже перекошено, но совсем в другую

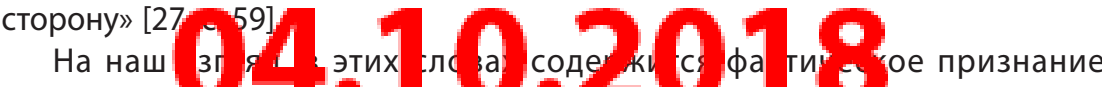
Г. А. Цукермап того фулдаментального чапта, что процесе развития имеет свою собственную логику, с которой должно считаться любое обучение, хотя как «педагогизированный» психолог она одновременно считает, что развитие может «искривляться» и «перекашиваться», что, следовательно, предполагает ориентацию на некие заданные педагогикой нормативы развития.

В этом случае отсутствие заранее планируемых позитивных результатов обучения рассматривается как асимметричное развитие, отклонение от развития, задержка развития и т. п. С нашей точки зрения, ответ на вопрос, правомерно ли говорить об «асимметричности» развития, будет положительным, если ориентироваться исключительно на существующие «нормы». Но ответ будет отрицательным, если понимать, что развитие 


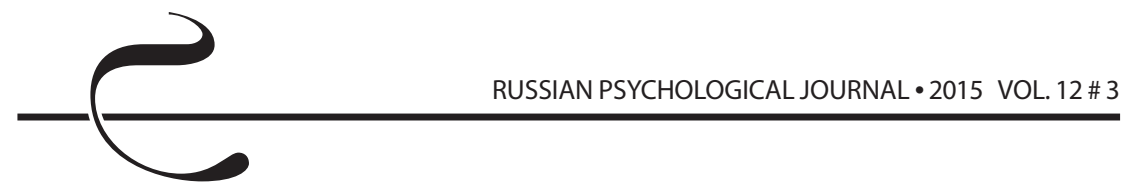

как объективный процесс может быть разным. И именно это НОРМАльно. Косвенным признанием этого фундаментального, на наш взгляд, положения явился отказ от терминов дефектологии при характеристике детей с особыми нуждами.

В этой связи нам неплохо бы вспомнить азы диалектического взгляда на развитие: «...Каждый прогресс в органическом развитии является вместе с тем и регрессом, ибо он зи: пппляет одностороннее развитие и исключает возможность развития во многих других направлениях» [20, т. 21, с. 621]. На мой взгляд, они точно схватывают объективную противоречивость процесса развития. Ее можно выразить следующим положением: развитие процесс объективный, и, действуя целенаправленно, мы должны понимать,

На наш взгляд, приведенные выше аргументы не только позволяют «развести» психологический и педагогический подходы к развитию, но делают актуальным по-новому раскрыть механизм развития.

Начнем с указания на тот фундаментальный факт, что, рождаясь, ребенок попадает в объективно существующую и определяющую его бытие систему общественного произвопства, которая в ходе его развития должна выступить

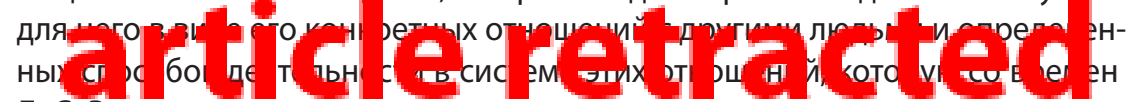
л. С. Выготского рассматривают как социальную ситуацию его развития.

В рамках подхода, развиваемого О. А. Карабановой, социальная ситуация развития рассматривается в двух аспектах: «объективная социальная позиция ребенка и система социокультурных ожиданий, норм, требований составляют объективный аспект социальной ситуации развития; система ориентирующих образов, определяющих отношения и сотрудничество ре-

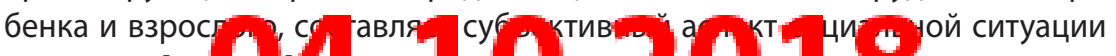
развития» $[15, .5$

Представляетя, одпако, что в слижившсися иселедсьательской практике эти аспекты как бы разделены между условным педагогом, фиксирующим внешние обстоятельства и факторы, значимые для ситуации воспитания, и условным психологом, акцентирующим внимание на межличностных отношениях ребенка и взрослых, на соответствующих переживаниях ребенка. В этом случае за скобками остаются те действительные общественные отношения, в которые де-факто включен ребенок, но которые, согласно Г. М. Андреевой, «носят безличный характер» $[2$, с. 71].

В этой связи стоит внимательнее проанализировать позицию Д. Б. Эльконина по данному вопросу и его концепцию периодизации в целом. Отметим определенный парадокс: концептуальные положения 
Д. Б. Эльконина обычно принимаются как хрестоматийные, при этом их методологические основания, служившие основой для разработки этих положений, в современной отечественной психологии игнорируются, как, вероятно, не соответствующие духу времени. Мы же считаем, что именно марксистская методология помогала Д. Б. Эльконину вскрывать глубинные основы психического развития ребенка, которые, однако, не получили должного и развернутого п пажения в самой концепции периодизации [30, с. 60-77]. Справедливости ради отметим, что сам Д. Б. Эльконин не считал свою концепцию законченной, так сказать, канонической конструкцией и, по сути, до конца своей жизни разрабатывал ее основные положения [29; 30, с. 480-519].

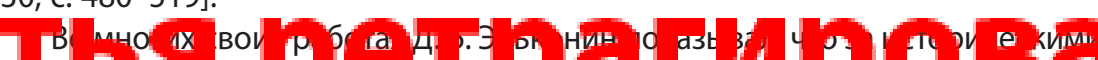

видеть изменения уровня развития общества, преждевсего развития его производительных сил, обуславливающих на каждом этапе своего развития соответствующую систему производственных отношений, с которой в ходе развития общества производительные силы вступают в противоречие, требующее смены сложившейся системы отношений.

В ходе этих изменений, как показал Д. Б. Эльконин, «связь ребенка

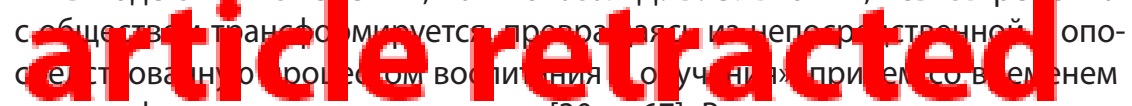
данные функции передаются семье [30, с. 67]. В этих условиях «система отношений "дети в обществе" вуалируется, закрывается системой отношений "ребенок-семья", а в ней - "ребенок-отдельный взрослый"» [30, с. 67].

Соглашаясь с такой интерпретацией, отметим, что в ней, к сожалению, не акцентируется тот важный момент, что сама семья есть прежде всего экономическая ячейка общества, и сам ребенок выступает членом общества, и, слег эте но, в-гда ил и эе и ик производи лt н ил, и уб ек ом пр из о ств нн « Тношений. Как известно, в носсии тоеле бтмено креписното права длй крестьян существовала юридически закрепленная практика выделения дополнительного земельного надела семье, в которой рождался ребенок мужского пола. Девочки же в крестьянских семьях рассматривались как обуза, «лишние рты». В Китае в деревнях вплоть до 50-х гг. прошлого века избавлялись от младенцев женского пола, отдавая их «в жены духу воды», т. е. попросту топили. В некоторых азиатских странах до сих пор существует, казалось бы, противоположный обычай требовать выкуп (калым) за будущую невесту, но в его основе та же, хотя и с другим вектором, логика отношения к ребенку как к «производительной силе». Именно это в первую очередь определяет социальную ситуацию его развития. 


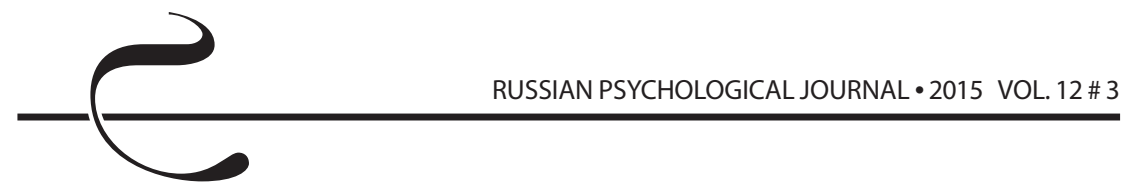

Подчеркнем: связь ребенка с обществом всегда двояко опосредствована, причем не столько процессом воспитания и обучения, реализуемым благодаря семье и другим социальным институтам, сколько его реальной жизнью и теми ее внутренними противоречиями, которые представлены в способе производства этой жизни в конкретной общности.

Это означает, что эта система отношений постоянно изменяется по мере становления ребенка в качлгтп «полноПРАВНОГО» субъекта отношений, реализующего определенные способы действия. Для иллюстрации можно напомнить статьи УК РФ о разных возрастах наступления для ребенка той или иной меры уголовной ответственности за совершенные им преступления. Таким образом ребенок с самого рождения становится производительной

необходимого изменения системы отношений, в которуювключен ребенок и в которой взрослые, а по мере развития и сам ребенок, постоянно учитывают изменения его возможностей как становящейся «производительной силы». Отметим однако, что статус ребенка как субъекта права в современном обществе многими даже не осознается: родителями ребенок подчас воспринимается как некто или даже как нечто, принадлежащее им. Между

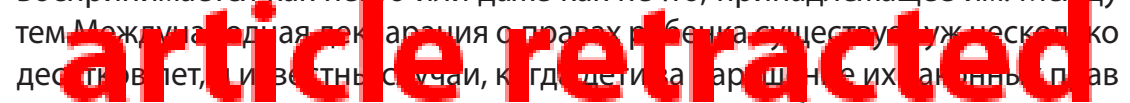
подавали в суд на родителей и выигрывали эти судебные процессы.

Представляется, что система отношений «ребенок-общество», которая, как отмечал Д. Б. Эльконин, «вуалируется» отношениями «ребенок-семья», точно так же «вуалируется» системой обучения, которому без достаточных оснований начинают приписывать роль источника развития. И хотя за этой «вуалью» скрытыми остаются реально действующие отношения ребенка как

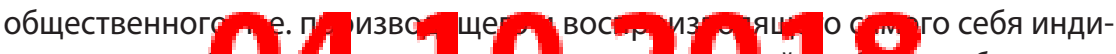

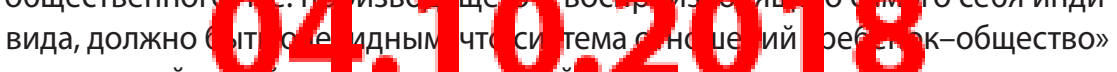

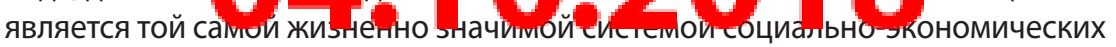
отношений, в которой осуществляется становление индивида как человека определенного рода и племени [23, 32, 34].

Отметим также, что система конкретных отношений ребенка не возникает из ничего, она порождается его общественной по содержанию и все более и более индивидуализирующейся по форме деятельностью в конкретных объективных обстоятельствах и условиях его жизни. Для того чтобы эти объективно существующие отношения стали его отношениями, должен возникнуть человеческий способ деятельности - то «зерно» развития, которое превращает его организменные нужды в человеческие потребности и тем самым задает определенный вектор развития. Удовлетворение или 
неудовлетворение этих потребностей определенным способом становится основным противоречием развития самого способа деятельности, а разрешение этого противоречия является источником развития деятельности в целом в том или ином направлении или векторе.

Вспомним в этой связи, что понятие «способ действия» в психологии введено С. Л. Рубинштейном, т. к. для него именно способ действия представлял собой "ту “клето':.'” ' ‘ли "ячейку", в которой можно вскрыть зачатки всех элементов психологии в их единстве» [25, с. 142].

При этом способ действия - это то, что человек реализует объективно, независимо от того, что́ он в связи с этим понимает или не понимает, что́ он осознает или не осознает. Более того, реальное действие, особенно в его

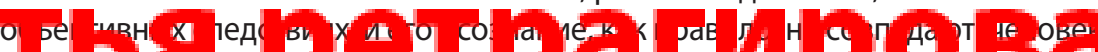

социальному организму, в котором его действия являются своеобразной «клеточкой». Известно, что Иоганн Кеплер открыл законы движения планет, исходя из представлений о том, что Господь, создавая мир, не мог сделать это иначе, нежели чем на основе гармонии сфер, движение которых рождало музыку. Любопытно, что дальнейшие открытия в астрономии, опиравшиеся, казалось бы, уже на точные вычисления, также строились на представлениях

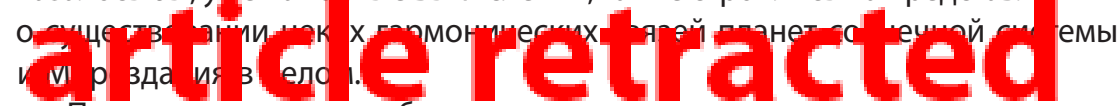

Поэтому для того, чтобы «вскрыть» механизм развития, надо увидеть, что за мотивами (потребностями) и способностями (психологическими возможностями субъекта) стоят реальные отношения субъектов совместной деятельности, которая всегда осуществляется определенными способами, адекватность которых этим отношениям есть сугубо временное состояние, что, собственно, и порождает объективную необходимость их изменения, которая так

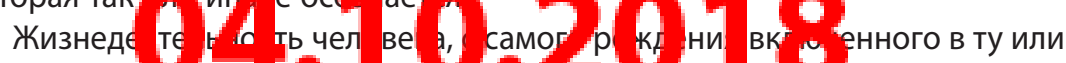
иную общност, осуществлетсл тольио о форме совместной деятельности [3], «клеточки» которой - конкретные способы действия - изначально «двухаспектны», т. е. их реализация является одновременно и реализацией системы отношений. В свою очередь, развитие этих способов и закономерное появление новых психологических возможностей деятельности объективно заставляет человека изменять прежние отношения и строить новую систему отношений посредством новых способов, направленных на выявление сущности этих вновь складывающихся отношений.

Описанные противоречия, возникающие в деятельности, имеют, так сказать, тотальный характер: антагонизм способов действия с той или иной системой отношений закономерно сопровождает всякое развитие - как 


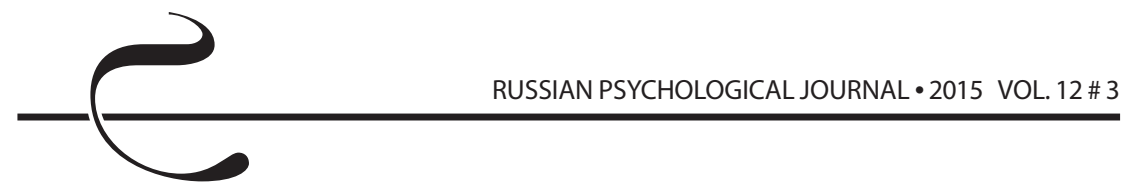

процесс отторжения старых форм деятельности при появлении ее нового содержания.

В контексте деятельности развитие способа, за которым стоит развитие соответствующей потребности, а, следовательно, мотива, ведет к тому, что возникает новая потребность, новый мотив. Например, комплекс оживления у младенца - потребность в другом человеке, появление которой свидетельствует о становлении гапэичной системы «осознанных» отношений, расширение или сужение которой, в свою очередь, ведет к мотивационной необходимости дальнейшего изменения способов его деятельности [19]. На самом деле это означает, что в его мире возникли другие люди - «партнеры» его новых отношений в данной общности и соучастники его совместной

мотивации деятельности, обуславливающей, в свою очередь, необходимое развитие способов действия и, соответственно, - деятельности в целом. При этом в системе мотивации всегда происходит «расщепление» мотивов: одни «повернуты» в прошлое, другие «повернуты» в будущее, что в действительности самой деятельности означает наличие соответствующих, порой противоречащихдруг другу способов действия.

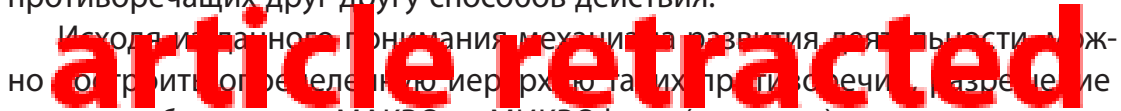
которых объясняет и МАКРО, и МИКРОфазы (моменты) развития деятельности, в каждом из которых представлены те или иные мотивационные диспозиции. Одни - устойчивы как характер [25], другие - мимолетны как смена настроений [17].

Если обратиться к известной схеме периодизации Д. Б. Эльконина, то представляется очевидным, что намеченные в ней линии действительно

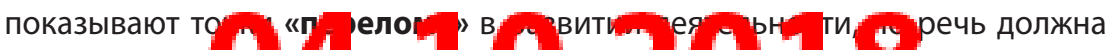
идти не о сме е е ди ра зит я оотив ди нl -пс ре с стной сферы периодом развития операционально-яекпических возможностей, как полагал Д. Б. Эльконин, а о «раздвоении» мотивации на два основных вида: мотивации построения и / или изменения отношений и мотивации смены способов деятельности, которые на определенных стадиях развития способов как новых возможностей субъекта вступают в противоречие со сложившейся и становящейся неадекватной для субъекта системой отношений. В концепции Д. Б. Эльконина оказались неотрефлексированными два важных момента. Зафиксировав, что на определенных этапах (младенец, дошкольник, подросток) возникает мотивация к «освоению» системы отношений «ребенок-общественный взрослый», Д. Б. Эльконин, к сожалению, не заметил возникновения мотивации к смене способов развивающейся деятельности, 
которые также возникают в определенные периоды, и посредством которых реализуется та или иная система отношений.

Подчеркнем еще раз, что Д. Б. Эльконин как истинный ученый не переставал размышлять над созданной им концепцией периодизации. Вот к какому выводу он приходит в 1983 г.: «Моя периодизация, хотя в основном и правильно схватывает динамику развития, но в ней не раскрыт внутренний механизм этой динами:...... [30, с. 519]. Д. Б. Эльконин понимал, что основой этого механизма должно быть существенное противоречие, которое он, однако, определяет следующим образом: «В структуре деятельности должно и не может не быть противоречия между ее мотивацией и ее операционально-технической стороной, которая есть непосредственно

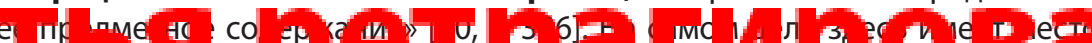

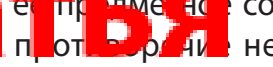
ер ka all $\mathrm{O}$, Q OMinia технической стороной, а противоречия между прежней ивновь возникающей мотивацией, что порой не дает человеку возможности действовать адекватно. Причем по большому счету само это противоречие - лишь «внешнее» выражение более глубинного противоречия между достигнутым уровнем развития способов действия и конкретными требованиями системы отношений, в которые включен и / или включается субъект деятельности на том

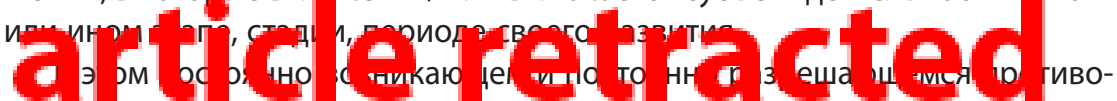
речии объективного воспроизводства форм деятельности для каждого отдельного индивида, становящегося конкретным представителем своего рода и племени, заключено психологическое «основание» развития человека, искомый психологический «механизм».

Выявляя в системе деятельности две подсистемы, две стороны: отношения «человек-человек» и отношения «человек-предмет», которые, по мнению

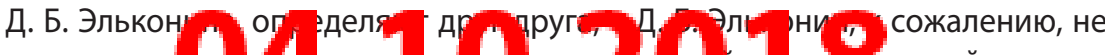
заметил, что ТV zе торон " с ть спект ен й й рти о ечивой системы способа производстьа.Яричинытодобпото раздвоєния, расщепления прежде «единого процесса жизни ребенка в обществе», с нашей точки зрения, следует искать в социально-исторических процессах: противоречия развивающегося общественного разделения труда «толкают» развитие деятельности каждого конкретного человека. Ребенка по мере развития его деятельности «втягивают» в новые системы отношений, что задает как изменение вектора развития, так и его содержания - с соответствующим изменением всей системы в целом: как системы способов, так и системы отношений, в которые включен или включается развивающийся человек. За этим исторически следует и то, что Д. Б. Эльконин назвал «расщеплением» образовательного процесса в школе «классового общества»: «Эту возможность и использует 




школа классового общества, воспитывая одних детей главным образом как исполнителей операционно-технической стороны трудовой деятельности, а других по преимуществу как носителей задач и мотивов той же деятельности [30, с. 69]. Представляется, однако, что Д. Б. Эльконин механически развел мотивационный и операционный аспекты трудовой деятельности в системе общественного производства. И в школе «классового общества» необходимо создавать усляпия для развития способов деятельности для «носителей задач и мотивов», тех же способов управления общественным производством, и развития определенной мотивации исполнителей для реализации операционно-технических возможностей.

Таким образом, двойственность процесса общественного производства,

стимулировала развитие способов, закономерно порождает двойственность процесса развития индивида: за счет развития способов деятельности происходит смена мотивации, ведущей к смене системы отношений, что, в свою очередь, за счет изменения социальной позиции человека необходимо порождает мотивацию к смене способов деятельности, открывая новую стадию развития "производительных» сил человека - порождения новых псијо вхождения в новую систему отношений, так и для мотивации овладения адекватными этим отношениям способами действия, которые призваны раскрывать «технологию» деятельности в новых отношениях, обеспечивая тем самым развитие самих способов. В качестве примеров развития мотивации первого типа можно привести ролевую игру - мотивационно значимую форму раскрытия смыслов того или иного способа деятельности, или вхождение в н р, о о ност осн а ая ши а, о рс ко и тусовка», вуз,

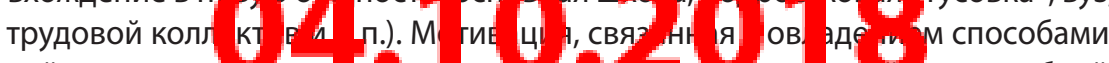
действия, развиьлется ь контекте предметпо-танипуляпивноиигры, учебной деятельности в начальной и старшей школе, вузе, спортивной, досуговой деятельности и др.

Характер мотивации может быть выявлен в рамках психологического анализа деятельности ребенка, однако в реальной практике его часто заменяет и подменяет педагогический подход с его стремлением «подтянуть» возникающую и выявляемую мотивацию к требованиям и ожиданиям соответствующих социальных институтов. В своих дневниковых записях Д. Б. Эльконин тонко подмечает это, указывая, что мотивационная готовность К «серьезной общественно значимой и общественно оцениваемой деятельности», появляющаяся накануне перехода ребенка в школу, не обязательно 
подразумевает учебную деятельность: «Удовлетворение данной тенденции в наших условиях происходит в школе. Оказывается, это удовлетворение безразлично к содержанию учебной деятельности. Деятельность может быть любой» [30, с. 500].

Отсюда вполне закономерен вывод, что эта мотивация означает не проявление готовности к школе, как до сих пор думает «школа» (педагогика), а мотивационную готов: г к изменению способов деятельности для достижения нового социального статуса, в который психологически человек уже вошел благодаря ролевой игре, раскрывшей для него значимость развития способов деятельности. А «школа» - лишь частная исторически конкретная форма для реализации возникшей мотивации.

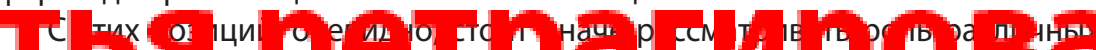

разования, подростковой общности и т. п. Если мы Говорим о развитии деятельности, то оно связано не просто с «прохождением» того или иного социального института, но представляет собой закономерный психологический продукт той конкретной деятельности, которую целенаправленно осуществляет человек в этих системах, ее, так сказать, психологический эффект, своегорода «побочный продукт», который мы не только не замечаем,


периодизации - понятием ведущей деятельности, введенным в отечественную психологию А. Н. Леонтьевым [17].

Постоянно размышляя и намечая пути углубления своей концепции периодизации, Д. Б. Эльконин, в частности, говорит о готовности «посмотреть так называемое деловое общение» в контексте отношений взрослого и ребенка младенческого возраста [30, с. 500].

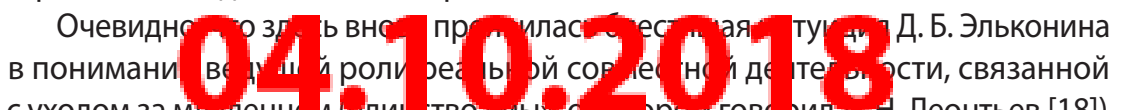
с уходом за младенцем (едићствожиы», о поторои говориля. Н. Леонтьев [18]). Именно эта совместная деятельность, объективно погруженная в систему реальных производственных отношений, связанных с обеспечением жизнедеятельности ребенка, является ведущей [4], а не то «непосредственноэмоциональное общение», которое традиционно принято считать «ведущей» деятельностью младенческого возраста [19]. В этом смысле и концепция ведущей деятельности «схватывает» лишь поверхность того процесса, который объективно имеет место в ходе осуществления деятельности, и который выступает на этой поверхности в виде тех или иных «новообразований». Заметим, что новообразования - это лишь явления, за которыми скрыта сущность развития деятельности. 
Таким образом мы приходим к выводу, что процесс развития деятельности субъекта, обусловленный постоянно возникающими социальноэкономическими противоречиями, которые объективны и закономерны для его совместной с другими деятельности, с психологической точки зрения выступает как процесс разрешения этих вызревающих в деятельности противоречий. Возникновение, усиление и разрешение данных противоречий с психологической точ:" п пния приводит к изменению мотивационнопотребностного основания деятельности субъекта, в котором психологически «отражается» объективное изменение его позиции в системе отношений, что, в свою очередь, либо актуализирует потребность в изменении сложившейся системы отношений, либо создает мотивацию трансформации сложившихся


в кризисах развития.

Таким образом, процесс развития - это всегда процесс развития деятельности. Можно говорить о «кольцевой», или «спиралевидной» структуре развития деятельности, которая всегда «погружена» в систему объективных отношений конкретного социума и «реализует» эти отношения [29, 31]. В этой «спиралевидности» прощесса с его противоречиями восходящих и нисходя-

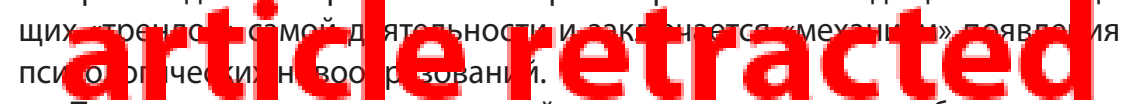

Применительно к педагогической практике отметим, что любое педагогическое воздействие как момент совместной деятельности на том или ином этапе развития может стать «развивающим», если с его помощью создаются условия, обеспечивающие объективно созревающие потребности в развитии мотивационно значимых способов деятельности или мотивационно значимые изменения позиции субъекта деятельности в системе отношений, требующих раз и ия о пси пог Р скихо м п ос й. Ю Го «развивающий» потенци $л$ е п зуется ии $b$ том $c$ у е, сли он с дет отвечать актуальным для данногоцикла или этага развиния потречностям - либо в смене способов деятельности, либо в смене сложившейся системы отношений, а также возможным перспективам развития.

С этой точки зрения обучение трактуется нами как целенаправленный процесс духовного производства, в котором в ходе совместной деятельности объективно развивающийся субъект изменяет сложившиеся ранее способы, что закономерно трансформирует деятельность субъекта и создает предпосылки для смены системы отношений, что, в свою очередь, определяет / изменяет вектор развития деятельности.

Отсюда - важность учета психологических закономерностей становления и развития деятельности, прежде всего содержания способов деятельности 
и их роли в развитии деятельности в целом. В этом случае вопрос о том, станет ли обучение «развивающим», определяется тем, насколько мотивационно значимы для личности операциональные возможности, развивающиеся у нее благодаря этому обучению. Сама оценка этих возможностей определяется спектром сложившихся и складывающихся «смысложизненных» ориентаций личности и перестройкой их иерархии в структуре личности $[15,17]$, которыми, тем самым, опредсппптся и возможные изменения вектора развития, и, соответственно, «развивающий» эффект обучения, и «воспитывающий» эффект воспитания.

\section{Литература}

2. Андреева Г. М.Социальная психология. Учебник для высших учебных заведений. - М.: Аспект Пресс, 1996. - 376 с.

3. Баттерворт Дж., Харрис М. Принципы психологии развития / Пер. с англ. - М.: Когито-центр, 2000. - 350 с.

4. Венгер А. Л. Психическое развитие ребенка в процессе совместной деятельности // Вопросы психологии. - 2001. - № 3. - С. 17-26.


А. М. Матюшкина. - М.: Педагогика, 1983. - С. 5-328.

6. Выготский Л. С. Проблема возраста // Собрание сочинений: в 6 т. - Т. 4: Детская психология / Под ред. Д. Б. Эльконина. - М.: Педагогика, 1984. С. 244-268.

7. Выготский Л. С. Проблема обучения и умственного развития в школьном возрасте // Выготский Л. С. Педагогическая психология / Под ред.

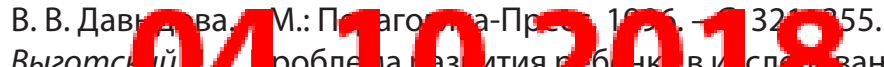

8. Выготс й робле иа аз ития ¿б нқ в V сл А заниях Арнольда Гезелла/ Гез-ляА. Педология рапнето возраста. Предисловие. Москва-Ленинград: УчГИЗ, 1932. - С. 12.

9. Гальперин П. Я. Методы обучения и умственное развитие ребенка. - М.: Изд-во Моск. ун-та, 1985. - 45 с.

10. Давыдов В. В. Теория развивающего обучения. - М.: ИНТОР, 1996. $544 \mathrm{c.}$

11. Дистервег А. Руководство к образованию немецких учителей / Дистервег А. Избранные педагогические сочинения. - М.: Учпедгиз, 1956. С. 136-203.

12. Дусавицкий А. К. Развивающее обучение: зона актуального и ближайшего развития // Начальная школа: плюс-минус. - 1999. - № 7. - С. 24-30. 


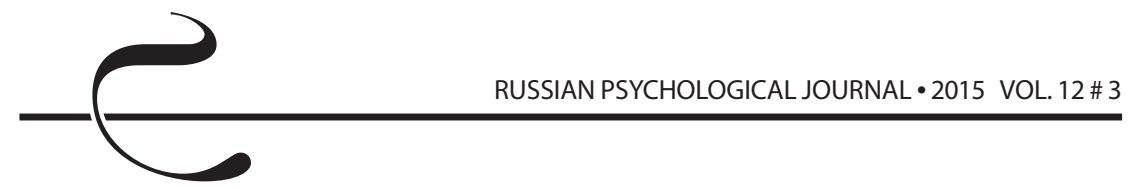

13. Занков Л. В. Избранные педагогические труды. - М.: Дом педагогики, 1999. -608 c.

14. Каптерев П. Ф. Избранные педагогические сочинения / Под ред. А. М. Арсеньева. - М.: Педагогика, 1982. - 704 с.

15. Карабанова О. А. Понятие «социальная ситуация развития» в современной психологии // Методология и история психологии. - 2007. - Т. 2. Вып. 4. - С. 40-56.

16. Кравцов Г. Г. Принцип единства аффекта и интеллекта как основа личностного подхода в обучении детей // Вопросы психологии. - 1996. № 6. - С. 53-64.

17. Леонтьев А. Н. Деятельность. Сознание. Личность. - М.: Политиздат, тическое исследование) // Вопросы психологии. - 1998. - С. 108-124.

19. Лисина М. И. Формирование личности ребенка в общении. - СПб.: Питер, 2009. - 320 с.

20. Маркс К., Энгельс Ф. Сочинения. В 50 т. - М.: Государственное издательство политической литературы, 1955-1981 гг.

21. Нечаев Н. Н. А. Н. Леонтьев и П. Я. Гальперин: диалог во времени //Во-


Вопросы психологии. - 2006. - № 3. - С. 3-22.

23. Нечаев Н. Н. Психология: Избр. психол. труды (Серия: Психологи России). - Москва; Воронеж: МОДЭК, 2014. - 400 с.

24. Обухова Л. Ф. Две парадигмы в исследовании детского развития // Вопросы психологии. - 1996. - № 5. - С. 38-50.

25. Рубинштейн С. Л. Основы общей психологии. - М., 1940. - 596 с.



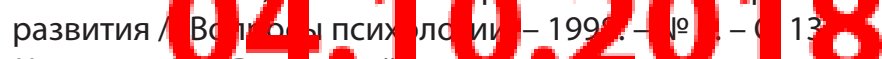

27. Цукерман І.я. Взаимодейитвие ребеппа и ьзросліго, творящее зону ближайшего развития // Культурно-историческая психология. - 2006. № 4. - С. 61-73.

28. Школа диалога культур. Идеи. Опыт. Проблемы/Под ред. В. С. Библера. Кемерово: АЛЕФ. Гуманитарный центр, 1993. - 416 с.

29. Эльконин Д. Б. Выдержки из научных дневников // Вопросы психологии. - 2004. - № 1. - С. 9-22.

30. Эльконин Д. Б. Избранные психологические труды / Под ред. В. В. Давыдова, В. П. Зинченко. - М.: Педагогика, 1989. - 560 с.

31. Fraser B. Getting Through the Terrible Twos / The successful parent // URL: http: // www.thesuccessfulparent.com 
32. Ganly S. The 5 Periods of Child Development / Yahoo! Contributor Network // URL: https: // contributor.yahoo.com

33. Iannelli V. Terrible Twos and Your Toddler. Ages and Stages / About.com Guide // URL: http: // beaguide.about.com

34. Kieninger R. Child Rearing in the Past // URL: http: // the-ultimate-frontier. org

35. Kiernan K. E., Huerta ^ $^{\prime} \sim$ Economic deprivation, maternal depression, parenting and children's cognitive and emotional development in early childhood // British Journal of Sociology. - 2008. - no. 59. - pp. 783-806.

\section{татья ретрагирована}

article retracted

\subsection{0 .2018}




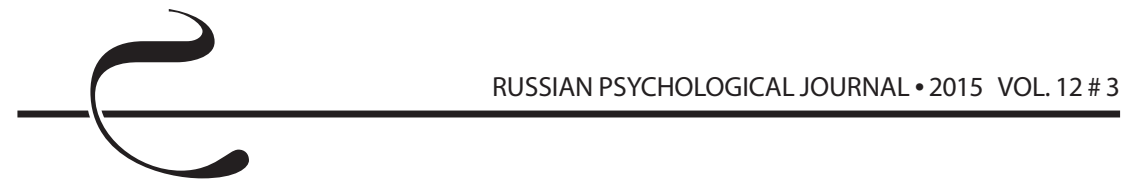

28. Sovremennye obrazovatelnye tehnologii: pedagogika i psihologiya. Kn. 15 [Modern educational technologies: pedagogy and psychology. Book 15]. Novosibirsk, Publishing house of Centre of Scientific Cooperation Development, 2014.

29. Sufiyanov V. V. Dialog kak pedagogicheskaya technologiya v smysloobrazuyuschem uchebnom kontekste. Avtoref. diss. ... kand. ped. nauk [Dialogue as pedagogical technology in ? sense-formation educational context. Abstr. Diss. ... Cand. of Ped. Sciences]. Rostov-on-Don, 2007, 23 p.

30. Murphy M. Sh. Better than best practice: Developing teaching and learning through dialogue. An Interview with Author, Dr. Adam Lefstein // Teaching and Teacher Education, 2014, no. 37, pp. 165-168.

\section{star if in a m $\mathrm{m}$}

\section{atc ion th co} co MPQBa

\section{DEVELOPMENT AND TEACHING: UNDER WHAT CONDITIONS TEACHING MAY BECOME “DEVELOPMENTAL"?

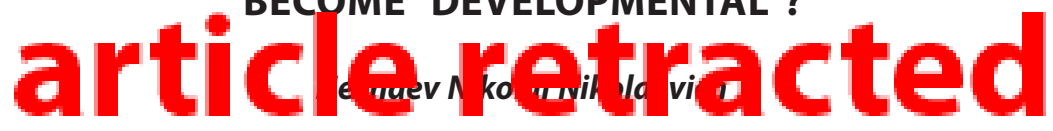

The article deals with methodological problems of the study of laws of the development of activities of the subject as an objective process and the role of training as a socially determined activity focused on the development of the subject of activity (based on a number of speeches by the author on the problem of interrelation between education and development in a number of International and All-Russian conferences in 2

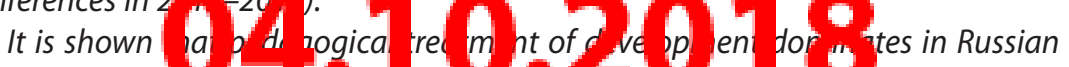
psychology; this is reflected in the chardcterisu of its main stages, which is based on the current structure of the education system, and also in understanding the very process of development as a process of adoption of social experience. Thus, they practically ignore the view on development as a process of self-motion of activity defined as "ripening" of internal contradictions of its implementation in a concrete socio-historical context, which structure, in turn, depends on a concrete society's mode of production and basic contradictions of its socio-economic development.

Taking into account that each individual entering this society as a person becomes a barrier of certain social dispositions, the "mechanism" of the development of his / her activity is defined as the resolution of contradictions when taking part in joint activity. From a psychological point of view these contradictions - depending on a stage 
and period of the development of activity - may be either a contradiction between the formed ways of action and the system of relations emerging in the activity of the subject (in which he / she is objectively involved from birth), or as a contradiction between the formed system of relations and forming modes of action, which in psychological terms are expressed in the differentiation of the person's motivational preferences at each stage of the development of his / her activities.

Special attention is paid +n the dependence of forms of manifestation of laws of the development process from concrete conditions and the content of the joint activity, when training is its particular form.

On the basis of the offered understanding of the mechanisms of the development of activities the author concludes that a "developing" nature of training is determined Tbsupet partuposa become motivationally significant for him / her.

Keywords: activity development, experience assimilation, periodization of development, cooperative activity, system of relations, ways of activity, sphere of motivation, mechanism of development, contradictions of development, developmental teaching.

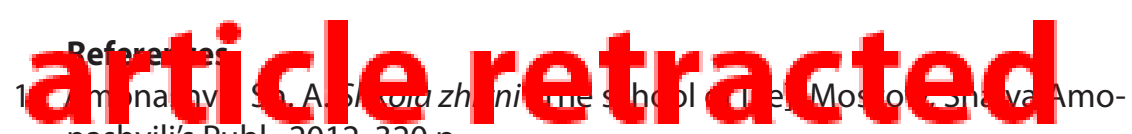
nashvili's Publ., 2012, 320 p.

2. Andreeva G. M. Sotsial'naia psikhologiia. Uchebnik dlia vysshikh uchebnykh zavedenii [Social psychology. Textbook for higher schools]. Moscow, Aspekt Press Publ., 1996, 376 p.

3. Butterworth J., Harris M. Printsipy psikhologii razvitiia [Principles of developmental psychology]. Moscow, Kogito-tsentr Publ., 2000, 350 p.

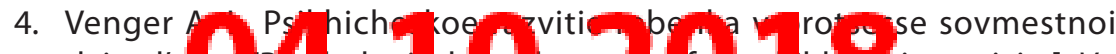
deiatel'n st if $\alpha$ holog al ev lopm it $f t$ e c ild s int activity]. Voprosy psikrologii - Approuches so Psycruorogy, 2001, ho. s, pp. 17-26.

5. Vygotskii L. S. Istoriia razvitiia vysshikh psikhicheskikh funktsii // Sobranie sochinenii: $v 6 t$. - T. 3: Problemy razvitiia psikhiki [The history of the development of higher mental functions. Collected works in 6 volumes. V. 3. Problems of mental development]. Moscow, Pedagogika Publ., 1983, pp. 5-328.

6. Vygotskii L. S. Problema vozrasta //Sobranie sochinenii: v 6 t. - T. 4: Detskaia psikhologiia [The problem of age. Collected works in 6 volumes. V. 4. Child psychology]. Moscow, Pedagogika Publ., 1984, pp. 244-368.

7. Vygotskii L. S. Problema obucheniia i umstvennogo razvitiia v shkol'nom vozraste // Vygotskii L. S. Pedagogicheskaia psikhologiia [The problem of 


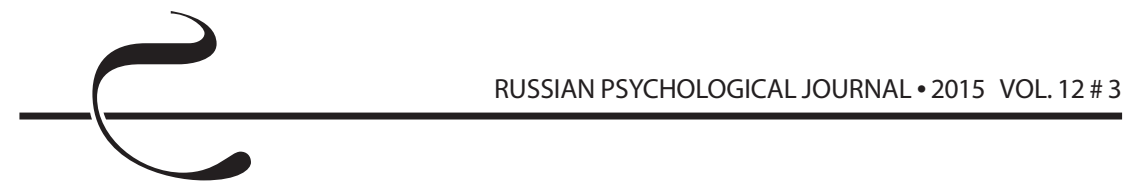

learning and mental development in school age. Vygotskii L. S. Pedagogical psychology]. Moscow, Pedagogika-Press Publ., 1996, pp. 321-355.

8. Vygotskii L. S. Problema razvitiia rebenka v issledovaniiakh Arnol'da Gezella / Gezell A. Pedologiia rannego vozrasta. Predislovie [The problem of child development in studies of Arnold Gesell. Gesell A. The pedology of early age. Preface]. Moscow-Leningrad, UCGIS, UChGIZ Publ., 1932, $12 \mathrm{p}$.

9. Gal'perin P. la. Metody obucheniia i umstvennoe razvitie rebenka [Methods of teaching and child mental development], Moscow, Moscow University Publ., 1985, 45 p.

10. Davydov V.V. Teoriia razvivaiushchego obucheniia [The theory of developing

Izbrannye pedagogicheskie sochineniia [A guide for education to German teachers. Diesterweg A. Selected pedagogical essays]. Moscow, Uchpedgiz Publ., 1956, pp. 136-203.

12. Dusavitskii A. K. Razvivaiushchee obuchenie: zona aktual'nogo i blizhaishego razvitiia [Developing education: the zone of actual and proximal development]. Nachal'naia shkola: plius-minus - Primary School: Plus-Minus, 1999,

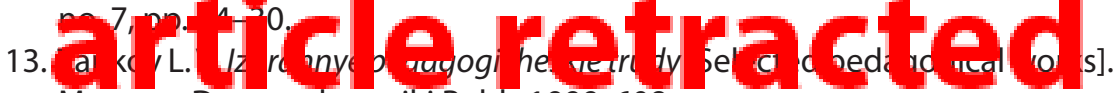
Moscow, Dom pedagogiki Publ., 1999, 608 p.

14. Kapterev P. F. Izbrannye pedagogicheskie sochineniia [Selected pedagogical works]. Moscow, Pedagogika Publ., 1982, 704 p.

15. Karabanova O. A. Poniatie "sotsial'naia situatsiia razvitiia" v sovremennoi psikhologii [The notion of "social situation of development" in modern psychology]. Metodologiia i istoriia psikhologii - Methodology and History

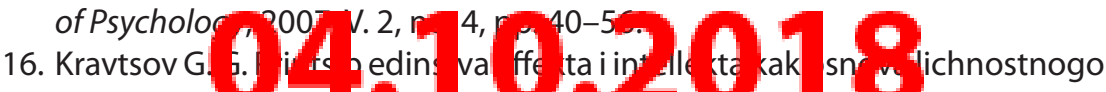
podkhoda vorouchenirdetei [The primere or unity of atreet and intellect as a basis for personal approach in the education of children]. Voprosy psikhologii - Approaches to Psychology, 1996, no. 6, pp. 53-64.

17. Leont'ev A. N. Deiatel'nost'. Soznanie. Lichnost' [Activity. Consciousness. Personality]. Moscow, Politizdat Publ., 1975, 304 p.

18. Leont'ev A. N. Uchenie o srede v pedologicheskikh rabotakh L. S. Vygotskogo (kriticheskoe issledovanie) [The theory of the environment in pedological works of L. S. Vygotskii (a critical study)]. Voprosy psikhologii - Approaches to Psychology, 1998, pp. 108-124.

19. Lisina M. I. Formirovanie lichnosti rebenka vobshchenii [The formation of child's personality in communication]. St. Petersburg, Piter Publ., 2009, 320 p. 
20. Marx K., Engels F. Sochineniia. V 50 t. [Works. In 50 volumes]. Moscow, State Publishing House of Political Literature Publ., 1955-1981.

21. Nechaev N. N. A. N. Leont'ev i P. la. Gal'perin: dialog vo vremeni [A. N. Leont'ev and P. la. Gal'perin: a dialogue in time]. Voprosy psikhologii-Approaches to Psychology, 2003, no. 2, pp. 50-69.

22. Nechaev N. N. Ochelovechivanie tvorchestva: problemy i perspektivy [Humanization of crea +i rity: problems and prospects]. Voprosy psikhologiiApproaches to Psychology, 2006, no. 3, pp. 3-22.

23. Nechaev N. N. Psikhologiia: Izbr. psikhol. trudy (Seriia: Psikhologi Rossii) [Psychology: collected psychol. works (Series: Psychologists of Russia)]. Moscow; Voronezh, MODEK Publ., 2014, 400 p. to Psychology, 1996, no. 5, pp. 38-50.

\section{Oiariting}

25. Rubinstein S. L. Osnovy obshchei psikhologii [Fundamentals of general psychology]. Moscow, 1940, 596 p.

26. Slobodchikov V. I., Isaev E. I. Antropologicheskii printsip v psikhologii razvitiia [The anthropological principle in developmental psychology]. Voprosy psikhologii-Approaches to Psychology, 1998, no. 6, P. 13.

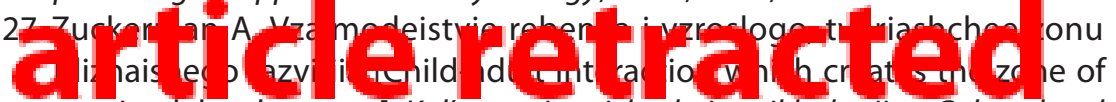
proximal development]. Kul'turno-istoricheskaia psikhologiia-Cultural and Historical Psychology, 2006, no. 4, pp. 61-73.

28. Shkola dialoga kul'tur. Idei. Opyt. Problemy [The school of the dialogue of cultures. Ideas. Experience. Problems]. Kemerovo, ALEF Publ., 1993, 416 p.

29. El'konin D. B. Vyderzhki iz nauchnykh dnevnikov [Extracts from scientific diaries]. Voprosy psikhologii - Approaches to Psychology, 2004, no. 1, pp. 9-22.

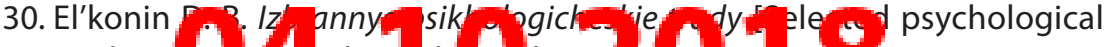

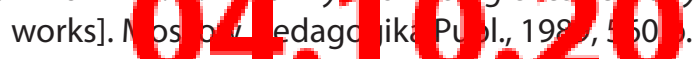

31. Fraser B. Getting Throug " the-rerrisle twost the successtul parent // URL: http: // www.thesuccessfulparent.com

32. Ganly S. The 5 Periods of Child Development / Yahoo! Contributor Network // URL: https: // contributor.yahoo.com

33. Iannelli V. Terrible Twos and Your Toddler. Ages and Stages / About.com Guide // URL: http: // beaguide.about.com

34. Kieninger R. Child Rearing in the Past // URL: http: // the-ultimate-frontier. org

35. Kiernan K. E., Huerta M. C. Economic deprivation, maternal depression, parenting and children's cognitive and emotional development in early childhood // British Journal of Sociology, 2008, no. 59, pp. 783-806. 